\title{
DESENVOLVIMENTO INICIAL DO MILHO (ZEA MAYS L.) \\ EM SUBSTRATO CONTENDO LODO DE ESGOTO COMPOSTADO
}

INITIAL DEVELOPMENT OF MAIZE (ZEA MAYS L.) IN SUBSTRATE WITH COMPOSTED SEWAGE SLUDGE

\section{Carla Andreia da \\ Cunha Martins (D)}

Pesquisadora pós-doutoral do Programa de Pós-Graduação em Tecnologia Ambiental da Universidade Federal Fluminense (UFF) Volta Redonda (RJ), Brasil.

\section{Fabiana Soares dos Santos (D)}

Professor associado do

Departamento de Engenharia de Agronegócios da UFF Volta Redonda (RJ), Brasil.

\section{Adriano Portz (D)}

Professor associado do Departamento de Engenharia de Agronegócios da UFF Volta Redonda (RJ), Brasil.

\section{André Marques dos Santos (iD}

Professor adjunto do Departamento de Bioquímica da Universidade Federal Rural do Rio de Janeiro (UFRRJ) - Seropédica (RJ), Brasil.

\section{Endereço para correspondência:}

Carla Andreia da Cunha Martins Avenida dos Trabalhadores, 420 Vila Santa Cecília - CEP 27255-125, Volta Redonda (RJ), Brasil E-mail: candcunha@yahoo.com.br

Recebido em: 16/11/2017

Aceito em: 08/05/2018

\section{RESUMO}

O uso de lodo de esgoto na produção vegetal tem se mostrado como uma alternativa promissora devido às elevadas concentrações de matéria orgânica e nutrientes presentes nesse material. O objetivo deste estudo foi avaliar o efeito de diferentes proporções de composto orgânico contendo lodo de esgoto na composição de substrato para o desenvolvimento inicial de plantas de milho em casa de vegetação. Os tratamentos constituíramse da compostagem (composto de lodo de esgoto e resíduo de poda urbana) e foram misturados com diferentes proporções de substrato comercial. A adição de composto de lodo de esgoto no substrato favoreceu o desenvolvimento das plantas de milho, avaliado pela produção de matéria seca de parte aérea e raiz, altura da planta, número de folhas, diâmetro de caule, desenvolvimento radicular e produção de pigmentos fotossintéticos. Esse maior desenvolvimento das plantas foi diretamente correlacionado com os maiores teores de N, Ca e Mg acumulados nas plantas.

Palavras-chave: biossólido; nutrientes; pigmentos fotossintéticos.

\section{ABSTRACT}

The use of sewage sludge in plant production has been a promising alternative due to the high concentrations of organic matter and nutrients present in this biosolid. The objective of this work was to evaluate the effect of different proportions of organic compound containing sewage sludge on the substrate composition for the initial development of corn plants in greenhouse. The treatments consisted of composting (composed of sewage sludge and urban pruning residue) mixed with different proportions of commercial substrate. The addition of sewage sludge in the substrate improved the development of corn plants, evaluated by dry matter production of shoot and root, plant height, leaf number, stem diameter, root development and photosynthetic pigment production. This higher development of the plants was directly correlated with the higher levels of $\mathrm{N}, \mathrm{Ca}$ and $\mathrm{Mg}$ accumulated in the plants.

Keywords: biosolid; nutrients; photosynthetic pigments. 


\section{INTRODUÇÃO}

Na última década, os investimentos em saneamento básico vêm aumentando no Brasil, incluindo sistemas de coleta e tratamento de esgoto, com o objetivo de atender às exigências ambientais. No processo de tratamento de esgoto, é gerado um resíduo sólido conhecido como lodo de esgoto, cujo gerenciamento é considerado complexo, com custos elevados, e sua disposição final inadequada pode comprometer os efeitos benéficos da coleta e do tratamento de esgoto. A utilização agrícola desse resíduo é uma alternativa prevista na legislação (BRASIL, 2006), por ser fonte de matéria orgânica e nutrientes para as plantas (ZHANG et al., 2015; LI et al., 2017), podendo resultar em benefício social, ambiental e econômico de disposição final.

No entanto, a presença de algumas substâncias inorgânicas e orgânicas, bem como agentes patogênicos, pode inviabilizar a sua utilização na agricultura. No Brasil, a Resolução CONAMA no 375/2006 (BRASIL, 2006) estabelece os limites máximos permitidos desses contaminantes para uso do lodo de esgoto na agricultura.

A presença de contaminantes inorgânicos e orgânicos é mais comum em lodo de esgoto gerado a partir de processos industriais contendo esses elementos. Estudos vêm mostrando que em lodo de esgoto urbano a presença desses contaminantes mostra-se abaixo dos níveis críticos restritivos para sua utilização agrícola, o que permite sua aplicação ao solo dentro de limitações toleráveis de impacto ambiental (SILVA; RESCK; SHARMA, 2002).

Com relação aos agentes patogênicos, a legislação sugere uma série de tratamentos com o objetivo de reduzir agentes patogênicos e atratividade de vetores, entre eles a compostagem, que é um processo de transformação biológica de materiais orgânicos, tais como paIha de arroz, café, papel etc., em fertilizantes orgânicos utilizáveis na agricultura (DORES-SILVA; LANDGRAF; REZENDE, 2013).

Diversos trabalhos têm mostrado aumento na produção de matéria seca, teores de nutrientes e produção de milho em solos tratados com lodo de esgoto (SILVA; RESCK; SHARMA, 2002; BARROS et al., 2011; RODRIGUES et al., 2011; GARCIA et al., 2012; BREMM et al., 2012), podendo ser considerado de forma a contribuir como fonte de nutrientes para diminuir os custos de produção, aumentando, assim, os lucros dos produtores, além de ser uma alternativa para agregar valor ao produto e reduzir os impactos ambientais de seu descarte.

O trabalho teve como objetivo avaliar a qualidade do composto orgânico, produzido a partir da mistura de lodo de esgoto e resíduos de poda provenientes da conservação de ruas e terrenos urbanos, em diferentes concentrações quanto aos teores de nutrientes e produção inicial de milho.

\section{METODOLOGIA}

O lodo de esgoto foi coletado em uma estação de tratamento de esgoto do município de Volta Redonda, Rio de Janeiro. Visando a reduzir as concentrações de coliformes termotolerantes (1.090.000 NMP.g ${ }^{-1}$ de ST) e Salmonella (59 P/A em $10 \mathrm{~g}$ de MS), que estavam acima dos valores permitidos pela legislação (BRASIL, 2006) para uso agrícola, foi realizada a compostagem como um processo de redução de patógenos.

O lodo de esgoto foi misturado com resíduos de poda provenientes da conservação de ruas e terrenos urbanos da cidade (compostos basicamente de galhos, folhas de árvores e grama, que foram triturados com tamanho médio de 0,5 cm), na proporção 19:1 (lodo de esgoto: poda urbana), de modo que a relação carbono/ nitrogênio ficasse em torno de 30.
O sistema de compostagem foi realizado em caixas d'agua de $1 \mathrm{~m}^{3}$ com aeração por meio de tubos perfurados com $1 \mathrm{~m}$ de comprimento e de 1" de diâmetro, para suprimento de oxigênio aos microrganismos responsáveis pela degradação da matéria orgânica e para controle de temperatura. Os compostos foram revolvidos e umedecidos manualmente, a fim de garantir aeração e umidade corretas para o processo de compostagem.

Após 120 dias de compostagem, os teores de coliformes termotolerantes foram reduzidos para $2,18 \mathrm{E}+02$ NMP. $g^{-1}$ de ST, valor abaixo dos limites máximos permitidos, e não foi encontrada Salmonella no material, demonstrando a eficiência do processo de compostagem na redução de patógenos e a possibilidade de utilização do lodo na produção vegetal. 
Em casa de vegetação, sementes de milho (Zea mays L.) da variedade Agroceres AG1051 foram semeadas em vasos de $8 \mathrm{~L}$ contendo os diferentes tratamentos constituídos da compostagem misturados com diferentes proporções de um substrato comercial, conforme descrição a seguir:

- Tratamento 0:1 (substrato comercial);

- Tratamento 1:2 (1 parte de composto de lodo de esgoto e resíduo de poda urbana:2 partes de substrato comercial);

- Tratamento 1:1 (1 parte de composto de lodo de esgoto e resíduo de poda urbana:1 parte de substrato comercial);

- Tratamento 2:1 (2 partes de composto de lodo de esgoto e resíduo de poda urbana:1 parte de substrato comercial);

- Tratamento 1:0 (1 parte de composto de lodo e resíduo de poda urbana).

O substrato comercial era composto principalmente por casca de pinus moída e compostada, e pó de coco, para produção de mudas utilizando-se 3 repetições para cada tratamento.
O experimento foi montado em um delineamento inteiramente casualizado, com 5 tratamentos e 3 repetições, totalizando 15 unidades experimentais. As características químicas dos diferentes tratamentos são apresentadas na Tabela 1.

As plantas foram colhidas 30 dias após a semeadura, momento em que foram avaliados os seguintes parâmetros: diâmetro do caule, altura da planta e número de folhas. Posteriormente, foram separadas em raiz e parte aérea, lavadas e levadas para estufa com circulação forçada de ar a $70^{\circ} \mathrm{C}$, para cálculo da produção de matéria seca.

Durante a coleta das plantas foram retirados discos foliares com $2,83 \mathrm{~cm}^{2}$ de área, os quais foram utilizados para extração dos pigmentos fotossintéticos utilizando-se dimetilsulfóxido (DMSO), de acordo com metodologia de Hiscox e Israelstam (1979). A quantificação dos pigmentos foi realizada com base nas leituras espectrofotométricas a $750 \mathrm{~nm}$ (turbidez), $665 \mathrm{~nm}$ (clorofila a), $649 \mathrm{~nm}$ (clorofila b) e $480 \mathrm{~nm}$ (carotenoides). Os valores obtidos foram expressos em concentração de pigmentos, segundo as equações propostas por Wellburn (1994).

Tabela 1 - Análises químicas dos teores totais e teores trocáveis do substrato formado com diferentes proporções de composto contendo lodo de esgoto e substrato comercial.

\begin{tabular}{|c|c|c|c|c|c|c|c|c|c|}
\hline \multirow{3}{*}{ Trat $^{1}$} & $\mathbf{N}$ & $\mathbf{P}$ & K & $\mathrm{Ca}$ & $\mathrm{Mg}$ & \multirow{3}{*}{$\begin{array}{l}\text { C } \\
\%\end{array}$} & \multirow{3}{*}{$\begin{array}{c}\text { MO } \\
\%\end{array}$} & \multirow{3}{*}{$\begin{array}{c}\text { Relação } \\
\text { C/N }\end{array}$} & \multirow{3}{*}{$\begin{array}{c}\begin{array}{c}\mathrm{pH} \\
\mathrm{H}_{2} \mathrm{O}^{*}\end{array} \\
1: 2,5\end{array}$} \\
\hline & \multicolumn{5}{|c|}{ Teores totais } & & & & \\
\hline & \multicolumn{5}{|c|}{ g. $\mathrm{kg}^{-1}$} & & & & \\
\hline $0: 1$ & 2,94 & 1,43 & 2,15 & 3,01 & 1,74 & 58,03 & 10,01 & 19,74 & 5,6 \\
\hline $1: 2$ & 4,29 & 2,05 & 2,20 & 9,91 & 1,67 & 84,73 & 14,61 & 19,75 & 5,8 \\
\hline $1: 1$ & 7,09 & 2,71 & 2,20 & 20,76 & 2,24 & 91,79 & 15,83 & 12,95 & 5,9 \\
\hline $2: 1$ & 8,14 & 3,26 & 2,19 & 25,45 & 2,69 & 116,69 & 20,12 & 14,34 & 6,0 \\
\hline $1: 0$ & 23,96 & 9,69 & 2,19 & 60,49 & 5,64 & 267,56 & 46,13 & 11,17 & 6,3 \\
\hline \multicolumn{10}{|c|}{ Teores trocáveis e disponíveis } \\
\hline \multirow{2}{*}{ Trat } & $\mathrm{Ca}$ & $\mathrm{Mg}$ & $\mathrm{Na}$ & $\mathrm{H}+\mathrm{Al}$ & Al & & & & \\
\hline & \multicolumn{5}{|c|}{$\mathrm{cmolc} \mathrm{dm}^{-3}$} & \multicolumn{4}{|c|}{$\mathrm{mg} \mathrm{dm}^{-3}$} \\
\hline $0: 1$ & 5,50 & 2,13 & 0,30 & 13,45 & 0,0 & \multicolumn{2}{|c|}{$1.323,41$} & \multicolumn{2}{|c|}{$1.720,21$} \\
\hline $1: 2$ & 14,00 & 8,38 & 0,55 & 12,13 & 0,0 & \multicolumn{2}{|c|}{$1.009,19$} & \multicolumn{2}{|c|}{$2.680,85$} \\
\hline $1: 1$ & 22,50 & 7,75 & 1,04 & 15,10 & 0,0 & \multicolumn{2}{|c|}{$1.018,44$} & \multicolumn{2}{|c|}{$3.455,32$} \\
\hline $2: 1$ & 24,75 & 10,25 & 0,92 & 11,72 & 0,0 & \multicolumn{2}{|c|}{889,05} & \multicolumn{2}{|c|}{$3.797,87$} \\
\hline $1: 0$ & 25,50 & 15,75 & 1,29 & 9,90 & 0,0 & \multicolumn{2}{|c|}{362,27} & \multicolumn{2}{|c|}{$4.492,55$} \\
\hline
\end{tabular}

${ }^{1}$ Proporção dos tratamentos - composto orgânico (formado por 19 partes de lodo de esgoto e 1 parte de resíduo de poda urbana):substrato comercial; N, P, K, Ca e Mg totais: Tedesco et al. (1995); *pH em água 1:2,5; carbono orgânico: método Walkley-Black; Ca e Mg trocáveis: $\mathrm{KCl} 1 \mathrm{~mol} \mathrm{~L}^{-1}$; P disponível, $\mathrm{K}$ e Na trocáveis: Mehlich-1; H+Al: acetato de cálcio (SILVA, 1999). 
A determinação de parâmetros radiculares, como comprimento e área de raízes, foi realizada seguindo a metodologia proposta por Brasil et al. (2000), sendo os dados processados no software SIARCS 3.0 (Embrapa-CNPDIA ${ }^{\circledR}$ ). Foram quantificados os valores de área superficial radicular em $\mathrm{cm}^{2}$ e o comprimento radicular total em $\mathrm{cm}$ de raízes por tratamentos.
Teores totais de N, P, K, Ca e Mg foram determinados na parte aérea e raízes das plantas, de acordo com Tedesco et al. (1995).

A análise de variância e os testes de médias foram realizados usando o programa SISVAR ${ }^{\circledR}$ (FERREIRA, 2011). Para análise de correlação, foi utilizado o programa ASSISTAT (SILVA; AZEVEDO, 2016).

\section{RESULTADOS E DISCUSSÃO}

Nas Figuras 1A e 1B são apresentados os dados de produção de matéria seca das plantas de milho nos diferentes tratamentos de compostagem misturados com substrato comercial. Observa-se que a adição de composto formado a partir da compostagem de lodo de esgoto e resíduos de poda urbana favoreceu o desenvolvimento das plantas de milho. No tratamento 0:1, formado por $100 \%$ de substrato comercial, o desenvolvimento das plantas foi significativamente menor, tanto da parte aérea quanto da raiz (Figuras $1 \mathrm{~A}$ e 1B), demonstrando a eficiência do composto no desenvolvimento das plantas. $O$ tratamento que obteve o maior desenvolvimento de parte aérea e da raiz foi o 2:1. Garcia et al. (2012), avaliando o crescimento e nutrição de milho decorrentes da aplicação de lodo de esgoto doméstico, observaram que as massas secas total e da parte aérea de milho aumentaram ao longo das fases fenológicas de cultivo nos três tratamentos aplicados (adubação mineral; lodo de esgoto; e lodo de esgoto + adubação mineral), sendo o tratamento com lodo de esgoto + adubação mineral o que apresentou resultados mais expressivos para o peso de sementes por vaso das plantas de milho (produção). Segundo Junio et al. (2013), o aumento das doses de composto de lodo de esgoto promoveu incremento na produtividade da cultura do milho, atingindo valor máximo de 4,63 t.ha-1 de grãos, com a aplicação de 75 t.ha-1 de composto.

A maior biodisponibilidade de nutrientes no solo (principalmente $\mathrm{N}, \mathrm{Ca}$ e $\mathrm{P}$ ) encontrada nos tratamentos com composto orgânico contendo lodo de esgoto (Tabela 1) provavelmente influenciou a maior produção de matéria seca nas plantas de milho. O milho é considerado uma planta exigente em termos nutricionais e, segundo Fia, Matos e Aguirre (2006), é uma das culturas com que se tem obtido os melhores resultados com uso do lodo de esgoto como fertilizante.

Corroborando os resultados obtidos, Silva et al. (2004), estudando o desenvolvimento de plantas de milho e eucalipto em solos com doses crescentes de composto formado a partir de lodo de esgoto e poda verde de árvore, demonstraram que o crescimento das plantas foi proporcional à quantidade de composto adicionado.

O desenvolvimento radicular do milho foi expresso em área e comprimento radicular (Figuras 1C e 1D). Observa-se que a adição de composto formado a partir da compostagem de lodo de esgoto e resíduos de poda urbana favoreceu o desenvolvimento radicular. No tratamento 0:1, formado por $100 \%$ de substrato comercial, a área radicular foi significativamente menor em relação aos demais tratamentos (Figura 1C), demonstrando a eficiência do composto no desenvolvimento das raízes. Com relação ao comprimento radicular, os tratamentos contendo somente substrato comercial $(0: 1)$ e somente composto de lodo de esgoto (1:0) obtiveram resultados significativamente menores com relação às diferentes misturas (Figura 1D), demonstrando o efeito positivo na melhoria das características agronômicas do substrato quando se adiciona lodo de esgoto ao substrato comercial. O tratamento que obteve o maior desenvolvimento radicular foi o 2:1. O estudo sobre raízes é muito importante para se entender o desenvolvimento e o crescimento da parte aérea das plantas, mas os procedimentos são trabalhosos, demandando habilidade e paciência, além da utilização critérios metodológicos para diminuir a variabilidade entre os tratamentos em estudo. Bassoi et al. (1994), avaliando a distribuição do sistema radicular do milho, verificaram que cerca de $70 \%$ das raízes de milho concentraram-se na camada de 0 a $40 \mathrm{~cm}$ de profundidade; independentemente do modo de aplicação de $\mathrm{N}$, os resultados de distribuição radicular foram obtidos por meio da técnica de análise do sistema radicular utilizando o SIARCS. Em outro estudo sobre a distribuição de raízes do milho, Fante Júnior et al., (1994) observaram que a quantificação radicular das plantas de milho mostrou maior concentração de raízes na camada de 0 a $20 \mathrm{~cm}$, cerca de $70 \%$ de massa seca para uma 
presença radicular de aproximadamente $40 \%$. O método de processamento de imagens mostrou-se como uma ferramenta importante no estudo detalhado sobre sistemas radiculares, podendo ser também aplicado às diversas áreas dentro da ciência agronômica (FANTE JÚNIOR et al., 1994). Sousa et al. (2002), estudando o sistema radicular do maracujazeiro, observaram redução do comprimento e da área radicular do maracujazeiro com a profundidade do perfil, e os maiores valores se concentraram na camada de 0 a 0,40 m. Entretanto, Lucas, Freizzone e Coelho Filho (2012) verificaram que o comprimento e a área de raiz de plantas de maracujá apresentaram maiores concentrações nas camadas variando de 0 até $0,50 \mathrm{~m}$ de profundidade. De acordo com os autores, as maiores áreas de raiz foram verificadas nas profundidades de 0 a $0,20 \mathrm{~m}$ e de 0,20 a $0,40 \mathrm{~m}$, variando de $7 \%\left(\mathrm{~K}_{1}\right.$ - adição de $0,200 \mathrm{~kg}$ de $\mathrm{K}_{2} \mathrm{O}$ por planta) a $34 \%$ ( $K_{2}$ - adição de $0,400 \mathrm{~kg}$ de $\mathrm{K}_{2} \mathrm{O}$ por planta) no perfil de solo estudado.

A

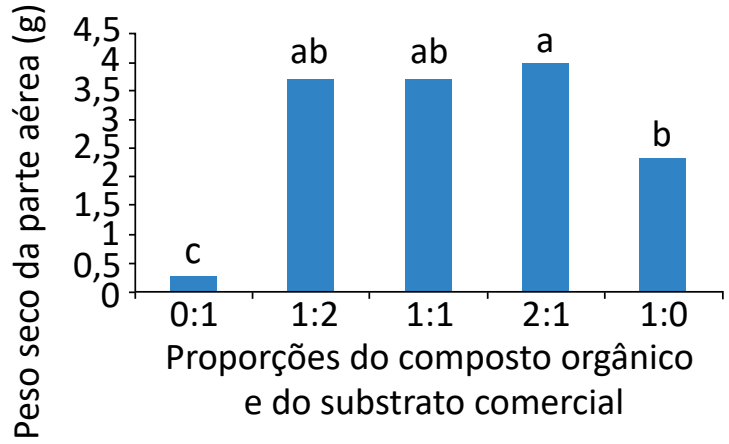

C

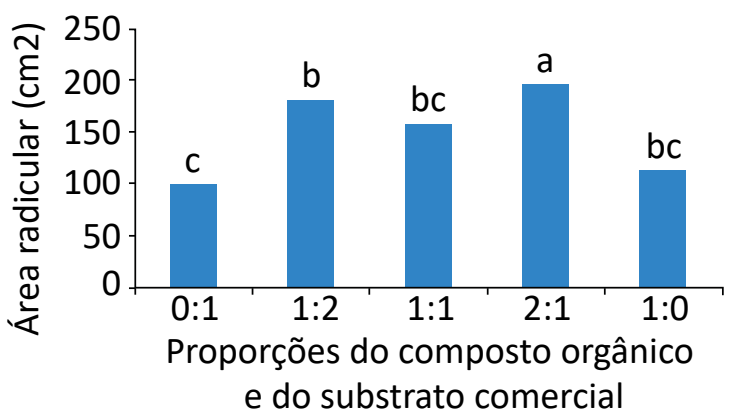

Na Figura 2 são apresentados os dados de altura $(\mathrm{cm})$, número de folhas e diâmetro do caule $(\mathrm{mm})$ das plantas de milho na época da colheita. Observa-se também que o tratamento $0: 1$, formado por $100 \%$ de substrato comercial, resultou em menor desenvolvimento das plantas em relação à altura da planta (Figura $2 \mathrm{~A}$ ), ao número de folhas (Figura 2B) e ao diâmetro do caule (Figura $2 \mathrm{C}$ ), corroborando os resultados de matéria seca (Figuras 1A e 1B). Portanto, a adição do composto formado por lodo de esgoto e resíduos de poda urbana favoreceu o desenvolvimento das plantas.

Observa-se aumento nas concentrações de $\mathrm{N}, \mathrm{Ca}$ e $\mathrm{Mg}$ (Tabela 2) na raiz e na parte aérea das plantas de miIho nos tratamentos com composto orgânico contendo lodo de esgoto, quando comparados ao tratamento somente com substrato comercial (0:1). Essa diferença foi mais expressiva quanto aos teores de $\mathrm{N}$, cujas concentrações foram bem inferiores no tratamento

B

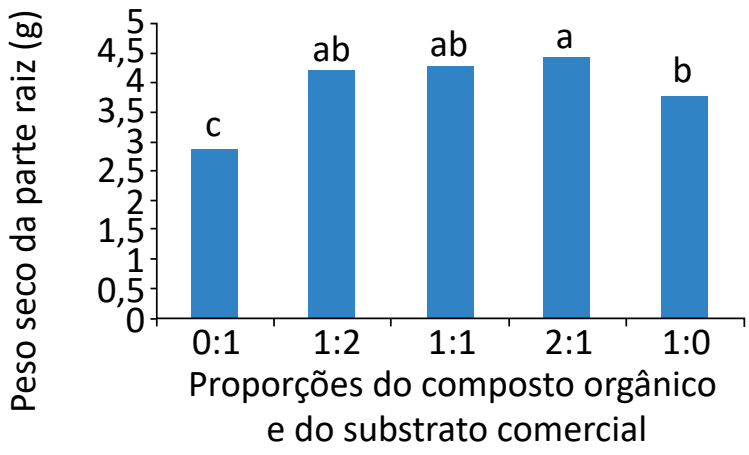

D

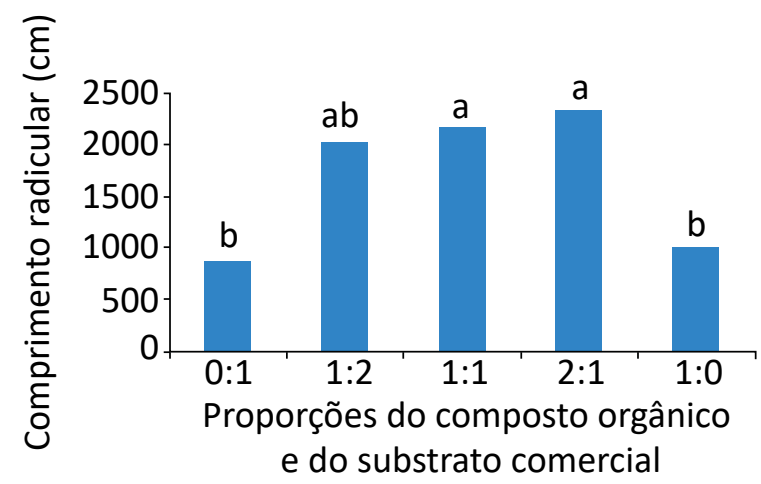

Figura 1 - Produção de matéria seca da parte aérea (A) e raiz (B); área (C); e comprimento radicular (D) de milho nas diferentes proporções de composto orgânico (formado por 19 partes de lodo de esgoto e 1 parte de resíduos de poda urbana) e substrato comercial $(0: 1 ; 1: 2 ; 1: 1 ; 2: 1 ; 1: 0)$. Letras iguais não diferem estatisticamente pelo teste de Tukey a $1 \%$ de significância. 
que não recebeu lodo de esgoto (0:1), que apresentou, consequentemente, menor produção de matéria seca (Figura 1), bem como desenvolvimento da parte aérea (Figura 2) e da raiz (Figuras 1C e 1D), além de sintomas visuais de clorose nas folhas. Barros et al. (2011), estudando a contribuição da adição de biossólidos na cultura do milho, encontraram resultados semelhantes, relacionando a deficiência de $\mathrm{N}$ ao pouco desenvolvimento da parte aérea e à senescência precoce das folhas mais velhas.

As maiores concentrações de N, P, Ca e Mg (Tabela 2) não foram relacionadas diretamente ao maior desenvolvimento da parte aérea da planta; inclusive, a produção de matéria seca da parte aérea (Figura $1 A$ ) e a altura da planta (Figura 2A) forneceram valores inferiores de produção, quando comparados aos dados obtidos com os tratamentos contendo misturas em diferentes proporções entre composto orgânico com lodo de esgoto e substrato comercial. Esse resultado provavelmente ocorreu devido à contribuição dada pela composição do substrato comercial, que forneceu melhores características para o desenvolvimento das plantas.

Junio et al. (2013) observaram que os teores de N, P e $\mathrm{K}$ nas folhas de plantas de milho aumentaram com a adição de 75 t.ha $^{-1}$ de composto de lodo de esgoto (considerada como a dose ótima recomendada). Nesse trabalho, os autores estudaram a produtividade de milho adubado com composto de lodo de esgoto e fosfato natural de Gafsa, e verificaram que, de modo geral, não houve influência da adubação fosfatada em relação aos teores de macronutrientes nos tecidos foliares. Segundo Garcia et al. (2012), a aplicação de lodo de esgoto doméstico e lodo de esgoto doméstico + adubação mineral proporcionou aumento dos teores foliares de $\mathrm{N}, \mathrm{Ca}, \mathrm{Mg}$, $\mathrm{P}, \mathrm{K}, \mathrm{S}, \mathrm{Zn}, \mathrm{Mn}, \mathrm{Cu}$ e B nas plantas de milho.

Na Tabela 2 observam-se os teores de pigmentos fotossintéticos nas folhas de milho; para as variáveis clorofila
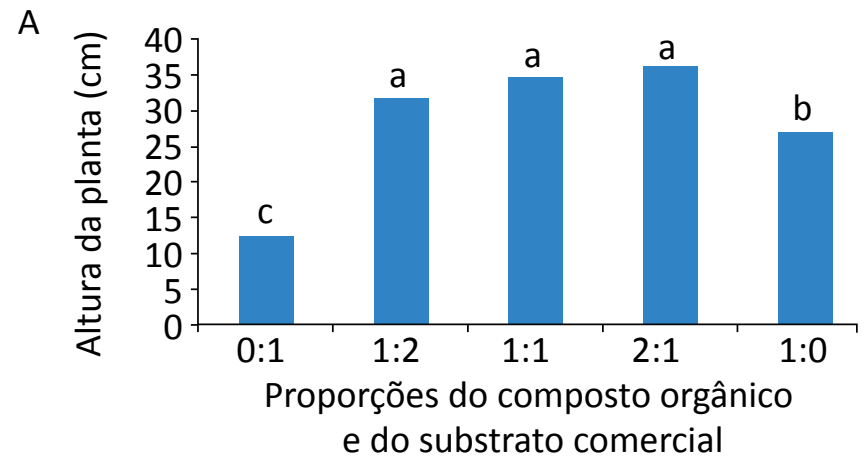
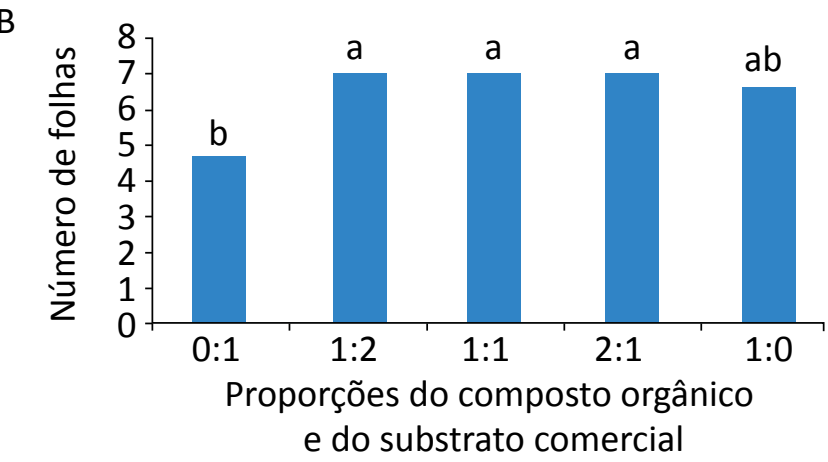

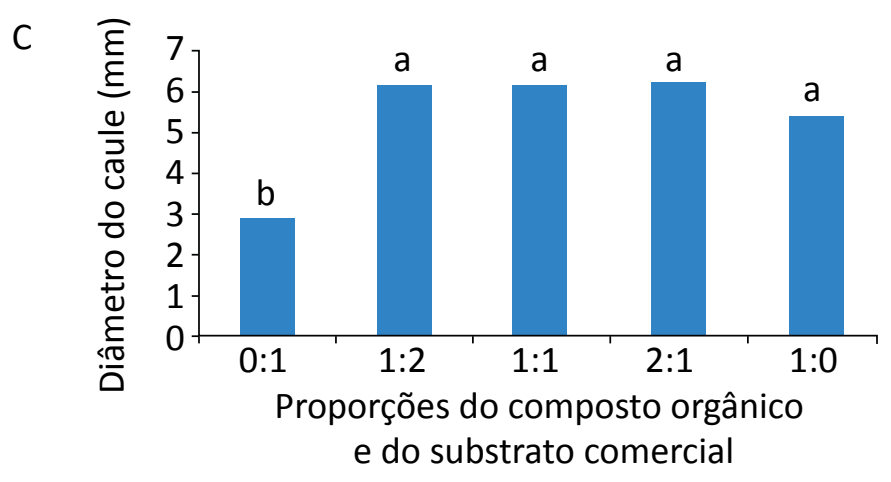

Figura 2 - Altura da planta (A); número de folhas (B); e diâmetro do caule (C) das plantas de milho nas diferentes proporções de composto orgânico (formado por 19 partes de lodo de esgoto e 1 parte de resíduos de poda urbana) e substrato comercial $(0: 1 ; 1: 2 ; 1: 1 ; 2: 1 ; 1: 0)$. Letras iguais não diferem estatisticamente pelo teste de Tukey a $1 \%$ de significância. 
a, clorofila total, carotenoides e razão entre as clorofilas $a$ e b, não houve diferença significativa entre os tratamentos contendo composto de lodo de esgoto em diferentes proporções $(1: 2 ; 1: 1 ; 2: 1$ e 1:0). O menor teor de todas as variáveis analisadas (Chla, Chlb, Ctotal, $\mathrm{Cx}+\mathrm{C}$ e razão entre $\mathrm{Chla/Chlb)} \mathrm{nas} \mathrm{folhas} \mathrm{de} \mathrm{milho} \mathrm{foi} \mathrm{verifi-}$ cado no tratamento $0: 1$, contendo $100 \%$ de substrato comercial (Tabela 2), cujos teores médios de clorofilas a, b e total foram aproximadamente cinco vezes inferiores aos tratamentos contendo composto de lodo de esgoto. Os maiores teores desses pigmentos nas folhas de miIho observados nos tratamentos contendo composto de lodo de esgoto devem estar relacionados aos maiores teores de $\mathrm{N}$ presente nesses tratamentos (Tabela 1 ), resultando em maior acúmulo desse elemento nas folhas das plantas (Tabela 2). O N é absorvido em maior quantidade pela cultura do milho e sua influência na fotossíntese pode ocorrer de várias formas, como pelo uso

Tabela 2 - Concentração de N, P, K, Ca e $\mathrm{Mg}\left(\mathrm{g} \mathrm{kg}^{-1}\right)$ na parte aérea e raiz das plantas de milho e teores de clorofilas a, b e total, carotenoides e razão entre clorofilas a e b nas folhas de milho (Zea mays L.) em tratamentos com diferentes proporções de composto orgânico contendo lodo de esgoto e substrato comercial.

\begin{tabular}{|c|c|c|c|c|c|}
\hline \multirow{3}{*}{ Tratamento* } & \multicolumn{5}{|c|}{ Parte aérea } \\
\hline & $\mathbf{N}$ & $\mathbf{P}$ & $\mathrm{K}$ & $\mathrm{Ca}$ & $\mathrm{Mg}$ \\
\hline & \multicolumn{5}{|c|}{ g. $\mathrm{kg}^{-1}$} \\
\hline $0: 1$ & $1,52 \mathrm{c}$ & $0,26 b$ & $7,22 d$ & $0,61 c$ & $0,50 c$ \\
\hline $1: 2$ & $3,03 b$ & $0,21 c$ & $7,98 c$ & $0,92 b$ & $0,92 b$ \\
\hline $1: 1$ & $3,74 b$ & $0,21 c$ & $9,50 b$ & $0,94 b$ & $0,92 b$ \\
\hline $2: 1$ & $3,56 b$ & $0,22 b c$ & $10,14 a$ & $1,01 b$ & $1,00 b$ \\
\hline \multirow[t]{4}{*}{$1: 0$} & $5,13 a$ & $0,33 a$ & $7,16 d$ & $1,23 a$ & $1,22 a$ \\
\hline & \multicolumn{5}{|c|}{ Raiz } \\
\hline & $\mathbf{N}$ & $\mathbf{P}$ & $\mathbf{K}$ & $\mathrm{Ca}$ & Mg \\
\hline & \multicolumn{5}{|c|}{ g. $\mathrm{kg}^{-1}$} \\
\hline $0: 1$ & $0,41 b$ & $0,07 d$ & $1,88 b$ & $0,69 c$ & $0,05 b$ \\
\hline $1: 2$ & $2,57 a$ & $0,11 c$ & $3,07 a$ & $0,94 b$ & $0,43 a$ \\
\hline $1: 1$ & $2,16 a$ & $0,13 b c$ & $3,16 a$ & $1,30 a$ & $0,48 a$ \\
\hline $2: 1$ & $2,34 a$ & $0,15 b$ & $2,70 a b$ & $1,50 a$ & $0,51 a$ \\
\hline 1:0 & $2,92 a$ & $0,20 a$ & $1,67 b$ & $1,56 a$ & $0,60 a$ \\
\hline \multirow{3}{*}{ Tratamento* } & \multicolumn{5}{|c|}{ Pigmentos fotossintéticos } \\
\hline & Chla & Chlb & Ctotal & $\mathrm{Cx}+\mathrm{c}$ & Chla/Chlb \\
\hline & \multicolumn{5}{|c|}{$\mu \mathrm{g} \cdot \mathrm{cm}^{-2}$} \\
\hline $0: 1$ & $4,14 \mathrm{~b}$ & $2,27 c$ & $6,41 b$ & $0,86 b$ & $1,82 b$ \\
\hline $1: 2$ & $21,16 a$ & $10,30 \mathrm{ab}$ & $31,46 a$ & $2,43 a$ & $2,06 a$ \\
\hline $1: 1$ & $20,08 a$ & $9,47 b$ & $29,55 a$ & $1,95 a$ & $2,12 a$ \\
\hline $2: 1$ & $21,12 a$ & $9,83 a b$ & $30,95 a$ & $2,18 a$ & $2,15 a$ \\
\hline 1:0 & $22,86 a$ & $11,10 a$ & $33,96 a$ & $1,93 a$ & $2,06 a$ \\
\hline
\end{tabular}

Letras iguais, na coluna, na mesma parte da planta e nos pigmentos fotossintéticos, não diferem estatisticamente pelo teste de Tukey a $1 \%$ de significância. *Proporções de composto orgânico (formado por 19 partes de lodo de esgoto e 1 parte de resíduos de poda urbana) e substrato comercial (0:1; $1: 2 ; 1: 1 ; 2: 1 ; 1: 0)$. Chla: teores de clorofila a; Chlb: teores de clorofila b; Ctotal: teores de clorofila total; Cx+c: carotenoides; Chla/Chlb: razão entre clorofilas a e b. 
na formação dos cloroplastos, na síntese proteica e na síntese de clorofila (ROCHA et al., 2016).

Observando-se a matriz de correlação (Tabela 3), verificou-se correlação positiva entre os tratamentos e o teor de $\mathrm{N}$ nas folhas de milho, indicando que os tratamentos com as maiores quantidades de composto de lodo de esgoto (Tabela 1) proporcionaram elevadas quantidades desse nutriente na parte aérea das plantas de milho.

Dessa forma, comprova-se a atuação do lodo de esgoto no suprimento de $\mathrm{N}$ para o cultivo de milho. Sabe-se que a taxa fotossintética é influenciada positivamen- te pela disponibilidade de N (DUBEY; RAGHUBANSHI; DWIVEDI, 2017). Portanto, o fornecimento adequado de $\mathrm{N}$ por meio da adição de composto de lodo de esgoto consiste em uma alternativa à utilização de fertilizantes minerais para manutenção das taxas fotossintéticas adequadas, resultando em melhor desenvolvimento da cultura.

Para as variáveis $\mathrm{N}$, Ca e $\mathrm{Mg}$ na parte aérea de milho (NPA, CaPA e MgPA), clorofilas a, b e total e razão entre Chla/Chlb, foi observado alto coeficiente de determinação a $1 \%$ de significância (Tabela 3), mostrando que os maiores teores desses nutrientes absorvidos pelas plantas nos tratamentos contendo composto de lodo

Tabela 3 - Matriz de correlações lineares simples entre as variáveis de plantas de milho.

\begin{tabular}{|c|c|c|c|c|c|c|}
\hline & TRAT $^{1}$ & NPA & PPA & KPA & CaPA & MgPA \\
\hline NPA & $0,9275^{* *}$ & & & & & \\
\hline PPA & $0,4548^{\text {ns }}$ & $0,4506^{\mathrm{ns}}$ & & & & \\
\hline KPA & $0,2362^{\mathrm{ns}}$ & $0,1226^{\mathrm{ns}}$ & $-0,6785^{* *}$ & & & \\
\hline CaPA & $0,9377^{* *}$ & $0,9679 * *$ & $0,4066^{\mathrm{ns}}$ & $0,1293^{\text {ns }}$ & & \\
\hline MgPA & $0,9153^{* *}$ & $0,9565^{* *}$ & $0,3226^{\text {ns }}$ & $0,1862^{\text {ns }}$ & $0,9830 * *$ & \\
\hline Chla & $0,7585^{* *}$ & $0,8359 * *$ & $-0,0143^{n s}$ & $0,3880^{\text {ns }}$ & $0,8839 * *$ & $0,9151 * *$ \\
\hline Chlb & $0,7536 * *$ & $0,8414 * *$ & $0,0172^{\text {ns }}$ & $0,3393^{\text {ns }}$ & $0,8893 * *$ & $0,9226 * *$ \\
\hline$C x+c$ & $0,4764^{\text {ns }}$ & $0,5625^{*}$ & $-0,2737^{\mathrm{ns}}$ & $0,4166^{\mathrm{ns}}$ & $0,6506 * *$ & $0,7012 * *$ \\
\hline Ctotal & $0,7572 * *$ & $0,8380 * *$ & $-0,0042^{\text {ns }}$ & $0,3726^{\text {ns }}$ & $0,8860 * *$ & $0,9179 * *$ \\
\hline Razão Chla/Chlb & $0,6717^{* *}$ & $0,6847^{* *}$ & $-0,2773^{\text {ns }}$ & $0,6839 * *$ & $0,7270 * *$ & $0,7548 * *$ \\
\hline & Chla & Chlb & $C x+c$ & Ctotal & \multicolumn{2}{|c|}{ Razão Chla/Chlb } \\
\hline \multicolumn{7}{|l|}{ NPA } \\
\hline \multicolumn{7}{|l|}{ PPA } \\
\hline \multicolumn{7}{|l|}{ KPA } \\
\hline \multicolumn{7}{|l|}{ CaPA } \\
\hline \multicolumn{7}{|l|}{ MgPA } \\
\hline \multicolumn{7}{|l|}{ Chla } \\
\hline Chlb & $0,9980 * *$ & & & & & \\
\hline$C x+c$ & $0,9079 * *$ & $0,9015^{* *}$ & & & & \\
\hline Ctotal & $0,9998^{* *}$ & $0,9991^{* *}$ & $0,9063 * *$ & & & \\
\hline Razão Chla/Chlb & $0,8989 * *$ & $0,8717^{* *}$ & $0,8510^{* *}$ & $0,8906 * *$ & & \\
\hline
\end{tabular}


de esgoto (Tabela 2) influenciaram diretamente a síntese de pigmentos fotossintéticos. Argenta et al. (2001), avaliando a correlação simples entre diferentes estádios de desenvolvimento de plantas de milho e teores de pigmentos fotossintéticos, observaram correlações positivas entre teor de $\mathrm{N}$ e clorofila extraível da folha, nos estádios de 10 a 11 folhas expandidas e de espigamento. Martins et al. (2010) verificaram que os teores de N-nitrato e N-amônio nas folhas de cultivares de batata apresentaram correlação alta e significativa com os teores de clorofila a e total extraíveis da batateira.

Apesar da significativa correlação entre os teores de nitrogênio (NPA), de cálcio (NCa) e de magnésio (MgPA) com os carotenoides, o coeficiente de determinação foi menor para $\mathrm{N}(0,5625)$, quando comparado ao $\mathrm{Ca}(0,6506)$ e ao $\mathrm{Mg}(0,7012)$, mostrando maior correlação do acúmulo de $\mathrm{Ca}$ e $\mathrm{Mg}$ na parte aérea com produção de carotenoides (Tabela 3). O Ca está ligado aos polissacarídeos na parede celular e à calmodulina, uma pequena proteína importante na sinalização e regulação das atividades de muitas enzimas. Tanto a alta concentração externa de Ca quanto a sua carga positiva bivalente criam um grande gradiente de potencial eletroquímico que favorece o movimento de Ca para dentro da célula, com isso, o Ca liga-se a proteínas, principalmente calmodulina, e a organelas intracelulares, como mitocôndria, núcleo, retículo endoplasmático (RE), e a organelas fotossintetizantes, os cloroplastos (EPSTEIN; BLOOM, 2006). Os maiores coeficientes de determinação encontrados para as clorofilas a e b com o $\mathrm{Mg}$ se justificam pelo elemento ser constituinte (parte integrante) das moléculas das clorofilas a e b.

\section{CONCLUSÕES}

O uso de composto orgânico formado a partir das diferentes proporções de lodo de esgoto e resíduos de poda urbana favoreceu o desenvolvimento das plantas de milho, mostrando o potencial fertilizante do composto obtido.

A proporção 2:1 (2 partes de composto de lodo de esgoto e resíduo de poda urbana:1 parte de substrato co- mercial) foi a que apresentou melhores resultados com relação ao desenvolvimento das plantas.

A adição de composto orgânico contendo lodo de esgoto favoreceu os teores de N, Ca e Mg nas folhas de plantas de milho, os quais influenciaram positivamente as taxas de pigmentos fotossintéticos sintetizados, resultando na melhoria do desenvolvimento das plantas.

\section{REFERÊNCIAS}

ARGENTA, G.; SILVA, P. R. F.; BORTOLINI, C. G.; FORSTHOFER, E. L.; STRIEDER, M. L. Relação da leitura do clorofilômetro com os teores de clorofila extraível e de nitrogênio na folha de milho. Revista Brasileira de Fisiologia Vegetal, v. 13, n. 2, p. 158-167, 2001. http://dx.doi.org/10.1590/S0103-31312001000200005

BARROS, I. T.; ANDREOLI, C. V.; SOUZA JUNIOR, I. G.; COSTA, A. C. S. Avaliação agronômica de biossólidos tratados por diferentes métodos químicos para aplicação na cultura do milho. Revista Brasileira de Engenharia Agrícola e Ambiental, v. 15, n. 6, p. 630-638, 2011. http://dx.doi.org/10.1590/S1415-43662011000600014

BASSOI, L. H.; FANTE JÚNIOR, L.; JORGE, L. A. C.; CRESTANA, S.; REICHARDT, K. Distribuição do sistema radicular do milho em Terra Roxa Estruturada Latossólica: II. Comparação entre cultura irrigada e fertirrigada. Scientia Agricola, v. 51, n. 3, p. 541-548, 1994. http://dx.doi.org/10.1590/S0103-90161994000300028

BRASIL. Conselho Nacional do Meio Ambiente. Resolução no 375. Define critérios e procedimentos, para o uso agrícola de lodos de esgoto gerados em estações de tratamento de esgoto sanitário e seus produtos derivados, e dá outras providências. Brasília: CONAMA, 2006.

BRASIL, F. C.; STOCCO, F. C.; PESSANHA, A. L.; SOUTO, R. L.; ZONTA, E.; ROSSIELLO, R. O. P. Distribuição e variação temporal de características radiculares de Brachiaria humidicola em um Planossolo Arenoso. In: REUNIÃO ANUAL DA SOCIEDADE BRASILEIRA DE ZOOTECNIA, 37., 2000. Anais... Viçosa, 2000. 
BREMM, R. R. R.; DAMASCENO, S. G.; SECCO, D.; VILAS BOAS, M. A.; TORRES, D. G. B.; MEES, J. B. R.; KUMMER, L. Potencial de uso de lodo de esgoto na cultura do milho em latossolo argiloso no oeste do Paraná. Revista Brasileira de Ciências Ambientais, n. 23, p. 17-24, 2012.

DORES-SILVA, P. R.; LANDGRAF, M.D.; REZENDE, M.O. O. Processo deestabilização de resíduosorgânicos:vermicompostagem versus compostagem. Química Nova, v. 36, n. 5, p. 640-645, 2013. http://dx.doi.org/10.1590/S0100-40422013000500005

DUBEY, P.; RAGHUBANSHI, A. S.; DWIVEDI, A. K. Relationship among specific leaf area, leaf nitrogen, leaf phosphorus and photosynthetic rate in herbaceous species of tropical dry deciduous in Vindhyan highlands. Annals of Plant Sciences, v. 6, n. 2, p.1531-1536, 2017. http://dx.doi.org/10.21746/aps.2017.02.001

EPSTEIN, E.; BLOOM, A. Nutrição mineral de plantas: princípios e perspectivas. Londrina: Ed. Planta, 2006. 403p.

FANTE JÚNIOR, L.; REICHARDT, K.; JORGE, L. A. C.; CRESTANA, S. Distribuição do sistema radicular do milho em Terra Roxa Estruturada Latossólica: I. Comparação de metodologias. Scientia Agricola, v. 51, n. 3, p. 513-518, 1994. http:// dx.doi.org/10.1590/S0103-90161994000300024

FERREIRA, D. F. Sisvar: a computer statistical analysis system. Ciência e Agrotecnologia, v. 35, n. 6, p. 1039-1042, 2011. http://dx.doi.org/10.1590/S1413-70542011000600001

FIA, R.; MATOS, A. T.; AGUIRRE, C. I. Produtividade e concentração de nutrientes e metais pesados em milho adubado com doses crescentes de lodo de esgoto caleado. Engenharia na Agricultura, v. 14, n. 1, p. 39-50, 2006.

GARCIA, G. O.; VENTURIN, A. Z.; RIBEIRO, H. R.; GONÇALVES, M. S.; SPADETTO, M. F. Crescimento e nutrição de milho decorrentes da aplicação de lodo de esgoto doméstico. Nucleus, v. 9, n. 1, p. 93-100, 2012. http://dx.doi.org/10.3738/ nucleus.v9i1.644

HISCOX, J. D.; ISRAELSTAM, G. F. A method for the extraction of chlorophyll from leaf tissue without maceration. Canadian Journal of Botany, v. 57, n. 12, p. 1332-1334, 1979. https://doi.org/10.1139/b79-163

JUNIO, G. R. Z.; SAMPAIO, R. A.; NASCIMENTO, A. L.; SANTOS, G. B.; SANTOS, L. D. T.; FERNANDES, L. A. Produtividade de milho adubado com composto de lodo de esgoto e fosfato natural de Gafsa. Revista Brasileira de Engenharia Agrícola e Ambiental, v. 17, n. 7, p. 706-712, 2013. http://dx.doi.org/10.1590/S1415-43662013000700003

LI, S.; LI, D.; LI, J.; LI, G.; ZHANG, B. Evaluation of humic substances during co-composting of sewage sludge and corn stalk under different aeration rates. Bioresource Technology, v. 245, p. 1299-1302, 2017. http://dx.doi.org/10.1016/j. biortech.2017.08.177

LUCAS, A. A. T.; FREIZZONE, J. A.; COELHO FILHO, M. A. Características da distribuição radicular de maracujazeiro sob fertirrigação. Irriga (Brazilian Journal of Irrigation and Drainage), v. 17, n. 2, p. 245-250, 2012. http://dx.doi. org/10.15809/irriga.2012v17n2p245

MARTINS, A. D.; COELHO, F. S.; LEÃO, A. B.; SILVA, C. C.; BRAUN, H.; FONTES, P. C. R. Relação entre índice SPAD, teores de clorofila e nitrogênio na folha de batata. Horticultura Brasileira, v. 28, n. 2, p. S835-S841, 2010.

ROCHA, D. M.; SOUZA, E. G.; NÓBREGA, L. H. P.; BAZZI, C. L.; GASPARIN, E. Correlação e dependência espacial de atributos do solo, índice de clorofila e produtividade do milho. RECyT, v. 18, n. 25, p. 62-69, 2016.

RODRIGUES, P. N. F.; ROLIM, M. M.; BEZERRA NETO, E.; COSTA, R. N. T.; PEDROSA, E. M. R.; OLIVEIRA, V. S. Efeito do composto orgânico e compactação do solo no milho e nutrientes do solo. Revista Brasileira de Engenharia Agrícola e Ambiental, v. 15, n. 8, p. 788-793, 2011.

SILVA, F. A. S.; AZEVEDO, C. A. V. The Assistat Software Version 7.7 and its use in the analysis of experimental data. African Journal of Agricultural Research, v. 11, n. 39, p. 3733-3740, 2016. https://doi.org/10.5897/AJAR2016.11522 
SILVA, F. C. Manual de análises químicas de solos, plantas e fertilizantes. Embrapa Solos. Brasília: Ed. Embrapa Comunicação para Transferência de Tecnologia, 1999. 370 p.

SILVA, J. E.; RESCK, D. V. S.; SHARMA, R. D. Alternativa agronômica para o biossólido produzido no distrito federal: IEfeito na produção de milho e na adição de metais pesados em Latossolo no cerrado. Revista Brasileira de Ciência do Solo, v. 26, n. 2, p. 487-495, 2002. http://dx.doi.org/10.1590/S0100-06832002000200023

SILVA, W. T. L.; SALLES, L. C.; NOVAES, A. P.; MARTIN NETO, L.; MILORI, D. M. B. P.; SIMÕES, M. L.; HANEDA, R. N.; FIALHO, F. L. Potencialidade do uso de composto produzido a partir do lodo de esgoto urbano e poda verde de árvore. São Carlos: Embrapa Instrumentação Agropecuária, 2004. 5 p. (Circular Técnica, 25.)

SOUSA, V. F.; FOLEGATTI, M. V.; COELHO FILHO, M. A.; FRIZZONE, J. A. Distribuição radicular do maracujazeiro sob diferentes doses de potássio aplicadas por fertirrigação. Revista Brasileira de Engenharia Agrícola e Ambiental, v. 6, n. 1, p. 51-56, 2002. http://dx.doi.org/10.1590/S1415-43662002000100010

TEDESCO, M. J.; GIANELLO, C.; BISSANI, C. A.; BOHNEN, H.; VOLKWEISS, S. J. Análise de solo, plantas e outros materiais. 2. ed. Porto Alegre: Ed. UFRGS, 1995. 174 p.

WELLBURN, A. R. The spectral determination of chlorophylls $a$ and $b$, as well as total carotenoids, using various solvents with spectrophotometers of different resolution. Journal of Plant Physiology, v. 144, n. 3, p. 307-313, 1994. https://doi. org/10.1016/S0176-1617(11)81192-2

ZHANG, J.; LV, B.; XING, M.; YANG, J. Tracking the composition and transformation of humic and fulvic acids during vermicomposting of sewage sludge by elemental analysis and fluorescence excitation-emission matrix. Waste Manage, v. 39, p. 111-118, 2015. https://doi.org/10.1016/j.wasman.2015.02.010 